\title{
Acoustic Signature Analysis and Sound Source Localization for a Three-Phase AC Induction Motor
}

\author{
Anand Krishnasarma, Seyed Jamaleddin Mostafavi Yazdi (D), Allan Taylor (D), Daniel Ludwigsen \\ and Javad Baqersad *
}

Citation: Krishnasarma, A.; Mostafavi Yazdi, S.J.; Taylor, A.; Ludwigsen, D.; Baqersad, J. Acoustic Signature Analysis and Sound Source Localization for a Three-Phase AC Induction Motor. Energies 2021, 14 , 7182. https://doi.org/10.3390/ en14217182

Academic Editor: Adolfo Dannier

Received: 6 September 2021

Accepted: 15 October 2021

Published: 2 November 2021

Publisher's Note: MDPI stays neutral with regard to jurisdictional claims in published maps and institutional affiliations.

Copyright: (c) 2021 by the authors. Licensee MDPI, Basel, Switzerland. This article is an open access article distributed under the terms and conditions of the Creative Commons Attribution (CC BY) license (https:// creativecommons.org/licenses/by/ $4.0 /)$.
NVH \& Experimental Mechanics Laboratory, Kettering University, 1700 University Avenue, Flint, MI 48504, USA; kris5470@kettering.edu (A.K.); smostafaviyazdi@kettering.edu (S.J.M.Y.); ataylor@kettering.edu (A.T.); dludwigs@kettering.edu (D.L.)

* Correspondence: jbaqersad@kettering.edu

\begin{abstract}
As part of the recent electrification of the transportation industry, internal combustion engines are being coupled with or replaced by electric motors. This movement towards an electrified drivetrain poses new noise, vibration, and harshness $(\mathrm{NVH})$ challenges related to electric motors. In this paper, the acoustic signature of an electric motor was analyzed to obtain a better understanding of the sound generated by these motors. This work provides an insight into an acoustic measurement technique that can be used to identify certain frequency bands that significantly contribute to the perceived sound. In the first part, the structural response of the motor was correlated with its acoustic spectra. Furthermore, data from acoustic and structural measurements were used to analyze the order content of the signal and identify critical contributors to the overall perceived sound. The differences between data captured by microphones in different positions around the motor helped to localize components of the overall sound. The results provide some discussion about techniques to decrease the overall sound. The technique described in this paper can be extended to fan-cooled motors that are used in vehicles such as golf carts or as auxiliary motors in electric/hybrid vehicles, as well as across a wide range of industrial applications.
\end{abstract}

Keywords: NVH; acoustics; electric motors; noise; sound source localization; vibrations

\section{Introduction}

The automotive industry is at the forefront of the electrification movement, and electric motors are being considered as alternatives to internal combustion (IC) engines. An electric vehicle $(\mathrm{EV})$ is quieter than an IC engine-powered vehicle. However, removing the IC engine reveals many other noise sources that were previously masked by the IC engine. The noise from road, wind, and powertrain are three major sources of noise in EVs. Electric motor noise or noise from the powertrain is significant at low speeds [1,2]. Despite low sound levels of EVs, high-frequency sounds from electric motors are known to produce a tonal sound that could prove to be a challenge from an NVH standpoint $[2,3]$. Furthermore, it has been shown the annoyance in motors has a strong inverse correlation to the quality and price [4]. Therefore, it is desirable to study the acoustic and structural response of motors to identify approaches for noise reduction or improve sound quality.

Researchers have used simulation techniques to reduce the effect of electromagnetic (EM) forces on the overall sound of the motor. EM simulation is imperative to predict radial and tangential forces in the air gap between the stator and rotor that cause the stator to deform and the housing to vibrate. Simulation models to analyze switched reluctance motors [5], permanent magnet motors [6,7], and induction motors [8] are already being developed. The forces from the EM simulation are used in acoustic and structural analyses to predict overall sound pressure levels (SPLs) from the motor and operating deflection shapes. These data were used to minimize interference with structural resonances [9]. While simulation and optimization of electric motors are of utmost importance before a 
design goes into production, experimental testing helps validate the simulation results and suggests further improvements to the overall functioning.

Experimental testing on electric motors is an integral part of the overall design phase. Experimental modal analysis and acoustic testing is used for vibration analysis of components and systems using both contact [10] and non-contact measurement techniques [11,12]. Most of the published empirical NVH research on electric motors studies the correlation of the test data to simulation studies [13-15]. Using vibration analysis for fault detection in electric motors is an area of ongoing research that helps tackle post-production noise and vibration-related issues [16-20]. Noise generated by rotating blades can be used for fault detection [21] and health monitoring. Researchers have used machine learning techniques to help in fault detection using acoustic data [22,23]. Acoustic microphone arrays have also been used to determine the sound intensity levels of a motor [24] and damage detection in wind turbines [25]. Most acoustic solutions and packages that are developed to reduce motor noise, especially during or just before the mass production phase, treat the path of sound rather than the source itself. With the help of sound-absorbing packages such as motor encapsulations [26] or software fixes that alter the inverter switching frequency to avoid exciting certain stator resonances, manufacturers can effectively reduce the electric motor's contribution to the overall sound heard in a vehicle's passenger cabin. However, reducing the sound generated by the electric motor can be much more effective than reducing the noise in the transfer path. Correlating the structural response of an electric motor to its acoustic response is very desirable for noise reduction and geometry optimization, but this has not been studied in the literature.

This paper investigated the correlation between structural and acoustical phenomena to identify some of the main contributors of sound generated by a three-phase AC induction motor. The work provides EMA (experimental modal analysis), OMA (operational modal analysis), and acoustic response of an electric motor. The paper also provides suggestions to reduce the overall perceived sound from an electric motor. Order analysis was also performed to provide an understanding of the content of the acoustic response. In the first phase, a modal analysis of the motor housing fixed at the base was performed using the impact hammer modal technique. Operational modal analysis was conducted on the motor running at a synchronous speed of 1800 RPM under no load. In the second phase, an acoustic signature analysis of the motor was carried out in a semi-anechoic chamber using microphones aligned in different directions and spaced equidistantly from the acoustic center. The data from microphones were used to make an estimation of sound contribution from different parts of the motor to localize the main source of sound generation. The structural and acoustic measurements were then correlated to identify the major contributors of the overall sound using spectral and order analysis.

\section{Noise from Electromagnetic Force}

In the development of electric motors for electric vehicle drive systems, there is increasing concern over the noises from motors. Electric motor noise sources can be grouped into three categories, namely, mechanical, electromagnetic, and aerodynamic. Mechanical noise arises from components such as bearings. Electromagnetic noise is a result of the interaction between electromagnetic flux waves and the resonance frequencies of the stator core. Aerodynamic noise is attributed to the sound generated by the passage of air around/through the motor [27].

An AC induction motor is made up of two main parts: the stator and the rotor. The polyphase windings on the stator, when fed with current, generate a rotating magnetic field in the air gap that induces a current in the rotor windings. The current in the rotor generates a magnetic field that interacts with the stator field, finally resulting in electromagnetic torque. The electromagnetic force has a radial and tangential component. Many researchers only consider forces in the radial direction as the primary source of stator deformation and vibration [28-30]. Magnetic permeability is the ability of an object or material to support the formation of magnetic fields, and because the magnetic permeability of the 
ferromagnetic core is much higher than that of the air gap, the magnetic flux lines are practically perpendicular to the stator and rotor cores, making the tangential component much smaller than the radial component.

The stator-frame or stator-enclosure structure is the primary radiator of the machine noise. If the frequency of the radial force is close to or equal to any of the natural frequencies of the stator-frame system, resonance occurs, leading to the stator system deformation, vibration, and acoustic noise [31].

\subsection{Structural Test Setup}

This section discusses the structural testing of the motor. To find structural sensitivities and resonances that could potentially be excited during the motor's operation, we performed experimental modal analysis (EMA) on the motor housing using the roving impact hammer technique. More information about the EMA and OMA can be found at $[32,33]$. A single-axis accelerometer was used to measure the response (see Figure 1). A total of 72 points were impacted in the radial direction, and the motor was fixed at the base. Load bearings act as a transmission path for structural vibrations, and the accelerometer was thus positioned close to the load bearings to ensure that most of the vibrations being transmitted to the housing through the bearings were captured. In the operational modal analysis, only the response is used, and the reference load is not measured. For the OMA (operational modal analysis) at a synchronous speed of 1800 RPM under no load, operational data were collected using a stationary accelerometer at point 54 (the same accelerometer location as seen in Figure 1) as a phase reference. An additional uniaxial accelerometer was roved over the other points. Acceleration data were sampled at 16,384 samples/second. The operational data collected as part were processed to extract the operational deflection shapes from the frequency domain in order to understand the motor's vibration pattern during operation. Spectra generated with a phase referenced signal ensured that phases between the fixed and roved accelerometers were properly accounted for.

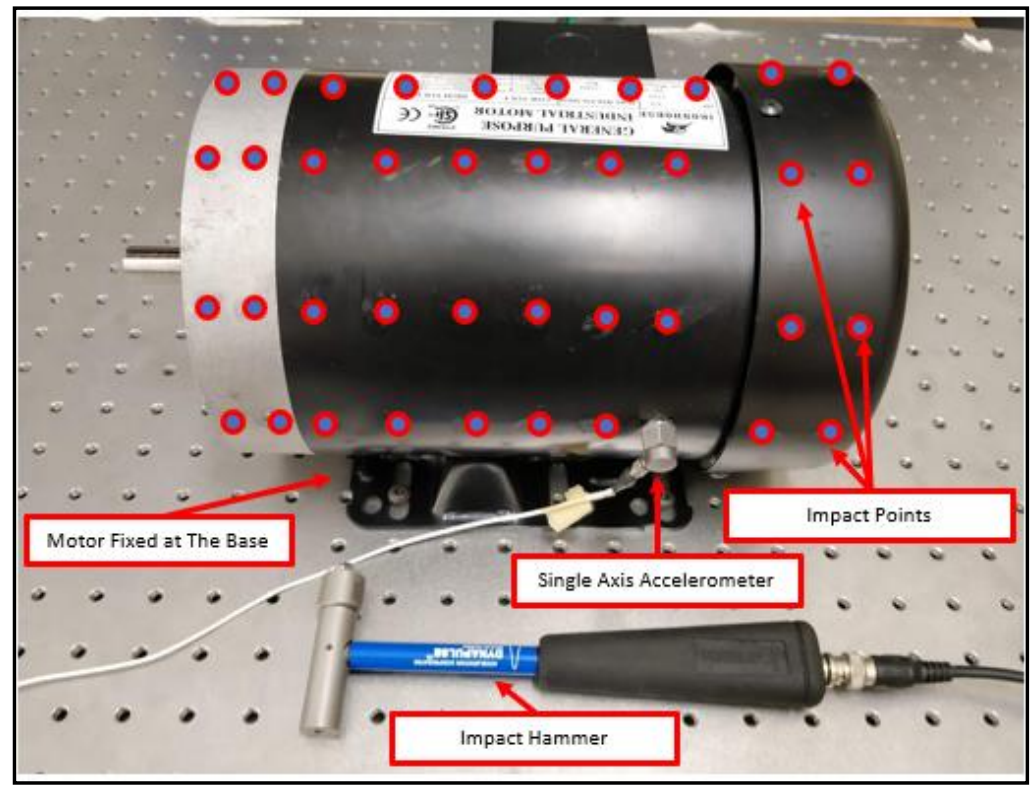

Figure 1. EMA test setup using the impact hammer technique on a motor fixed to the base.

\subsection{Test Setup for Acoustic Measurement}

For this work, a semi-anechoic chamber was used to acoustically characterize the behavior of a three-phase induction motor. The dimensions of the semi-anechoic chamber were $3.5 \times 3.5 \times 3.0 \mathrm{~m}$, and its cut-off frequency, or the lowest frequency at which the chamber exhibits anechoic characteristics, was $140 \mathrm{~Hz}$. Three microphones were used to collect acoustic data, namely, the microphone facing the shaft side, the microphone 
facing the fan side, and the microphone radially aligned with the motor housing, as seen from Figures 2 and 3. More information about the test setup can be found in [34]. The motor was set on an optical table and fixed at the base using fasteners (to replicate its operating condition), and the microphones were set $400 \mathrm{~mm}$ away from the acoustic center. A windscreen was used on the shaft side microphone to lessen the impact of wind noise due to the deflection of air by the end bracket around the fan.

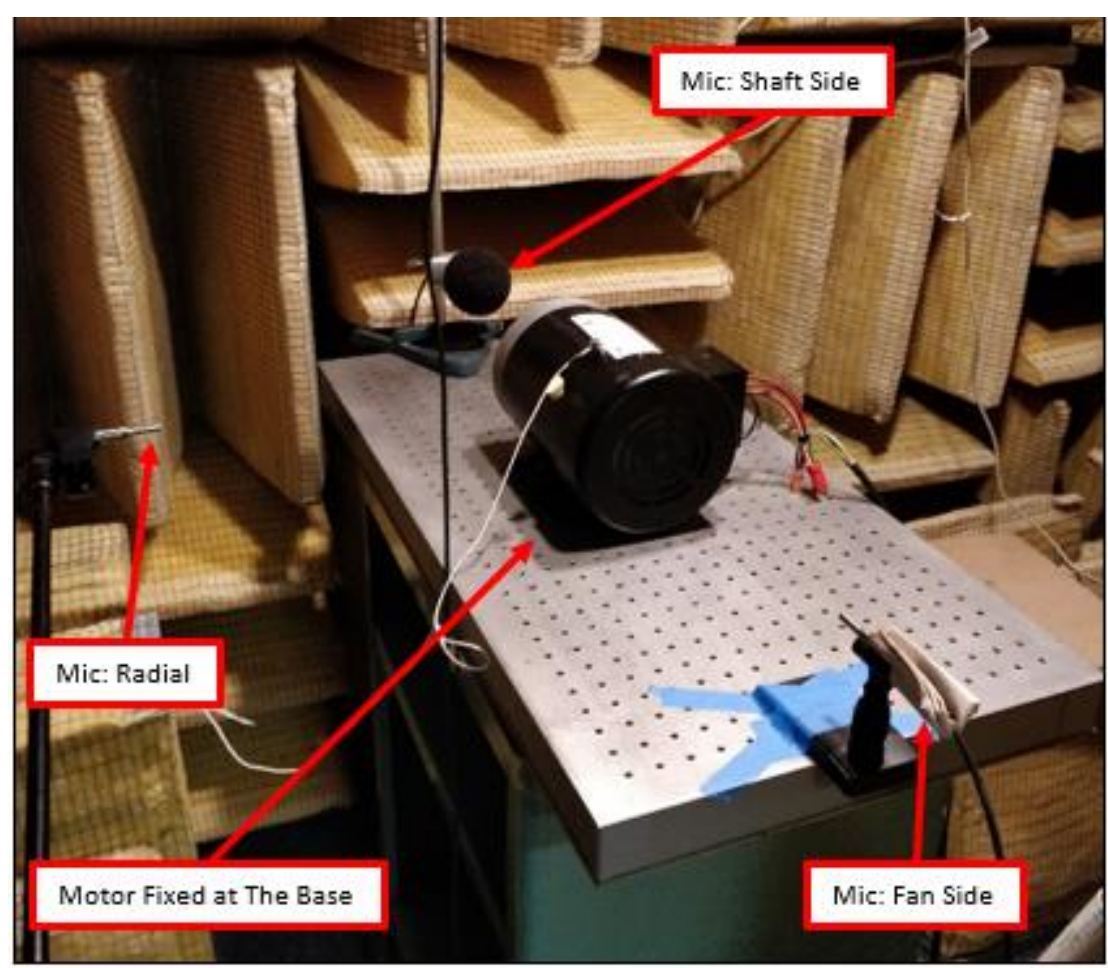

Figure 2. Acoustic measurement setup in the semi-anechoic chamber.

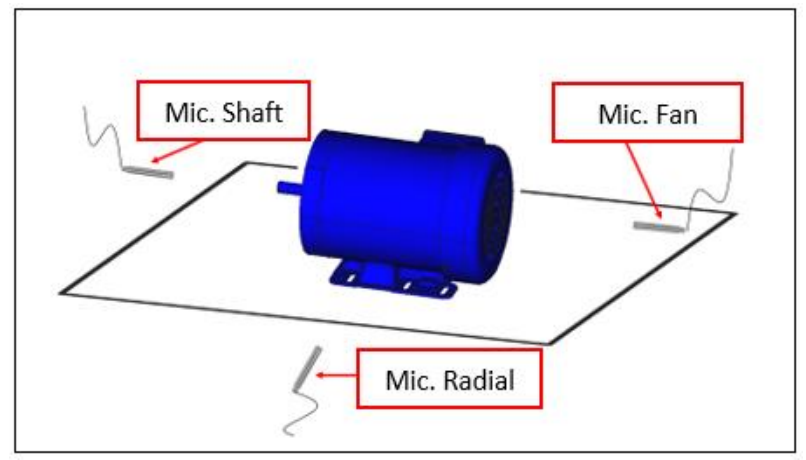

Figure 3. Schematic of motor setup and microphone positions.

The motor was then powered using a variable-voltage variable-frequency inverter to enable a range of operating speeds by changing the line frequency to the motor. The switching frequency of the pulse-width modulation (PWM) used was $10 \mathrm{kHz}$. Because the variable-voltage variable-frequency inverter was placed outside the semi-anechoic test chamber, components in the circuit producing the tonal sound due to electromagnetic excitation at the switching frequency were well isolated. On the other hand, in an electric vehicle, care must be taken to isolate the effect of the PWM's switching frequency from the main cabin.

Acoustic measurements were taken at line frequencies corresponding to 600, 900, 1200,1500 , and 1800 RPM at no load, and they are compared to each other as explained 
in Section 4. Sound pressure data were sampled at 16,384 samples/second, and each measurement lasted for $60 \mathrm{~s}$. A fast Fourier transform (FFT) was performed to analyze the measured sound pressures in the frequency domain. Each operating condition was carried out three times to ensure that the behavior of the motor was consistent at a given speed.

\section{EMA and OMA Results}

Figure 4 presents the summation of frequency response function (FRF) measured on all 72 impacted points. A can be seen in Figure 4, there were some prominent flexural modes at 424, 1048, 1164, 1704, and $3412 \mathrm{~Hz}$. The low-frequency peak at $71 \mathrm{~Hz}$ in Figure 4. can be attributed to the rigid body frequencies associated with the motor and the base. As shown in Figure 4, the operational modal analysis (OMA), measured using two uniaxial accelerometers that measured acceleration in the radial direction and an optical tachometer with a $\pm 1 \%$ uncertainty at $1743 \mathrm{RPM}(29 \mathrm{~Hz})$, highlighted the resonances of experimental modal analysis at 424, 1048, and $1164 \mathrm{~Hz}$. Resonances at 1704 and $3412 \mathrm{~Hz}$ observed in the EMA were not well excited at the 1743 RPM operation of the motor.

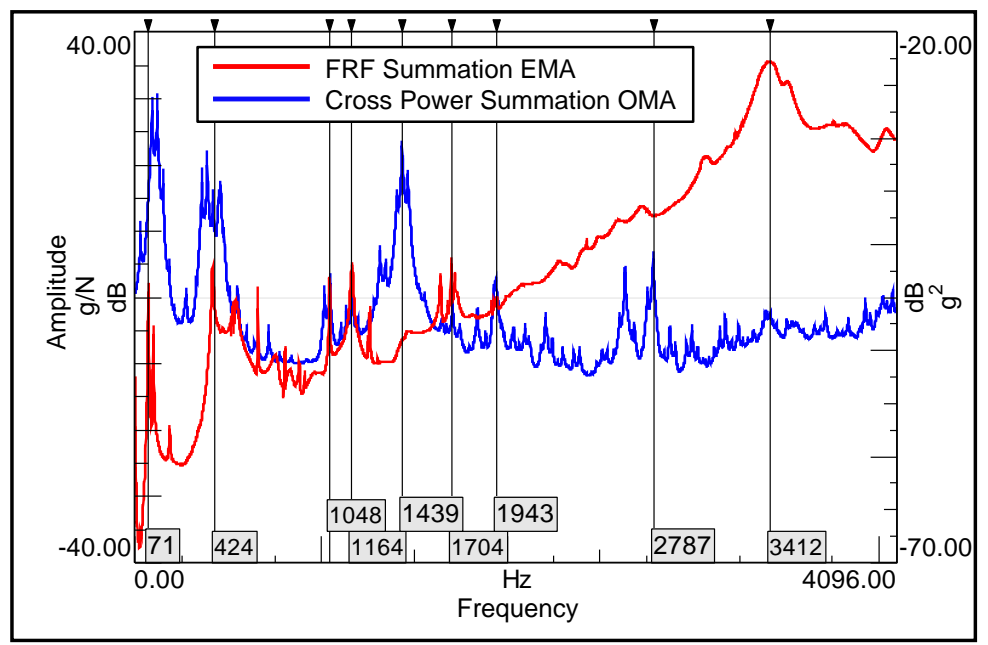

Figure 4. FRF summation from EMA and cross power summation from OMA.

In addition to these frequencies, the OMA revealed increased levels of vibration, especially around 1439 and $2787 \mathrm{~Hz}$. The resonances at around 425 and $1439 \mathrm{~Hz}$ from the OMA could be an effect of stator deformations that can be attributed to radial dynamic electromagnetic forces generated in the air gap between the rotor and stator. The radial electromagnetic force is directly proportional to the normal component of the flux density, which is represented by Tesla (T), and inversely proportional to the permeability of free space.

A simplified motor geometry, as seen in Figure 5, was created in LMS Test.lab using nodes and triangular surfaces in order to animate the operating deflection shapes. Operating deflection shapes at a synchronous speed of 1800 RPM under no load shown in Figure 6a-e help visualize deformation at different points on the motor at some of the natural frequencies highlighted in Figure 6. At approximately $424 \mathrm{~Hz}$, as seen from Figure 6a, the housing and the end bracket deformed and caused a yawing motion. The deformation at $1439 \mathrm{~Hz}$, seen in Figure 6b, was dominated by a partial ovalization of the end bracket. Both these lightly damped natural frequencies could be a product of electromagnetic excitation. At $1943 \mathrm{~Hz}$ (Figure 6d), the entire housing was seen to be deforming in a breathing motion, in which the majority of points deformed in phase in the radial direction. Figure 6 shows the operating deflection shape at $2787 \mathrm{~Hz}$, which was a more complex deformation of both the housing and the end bracket. 


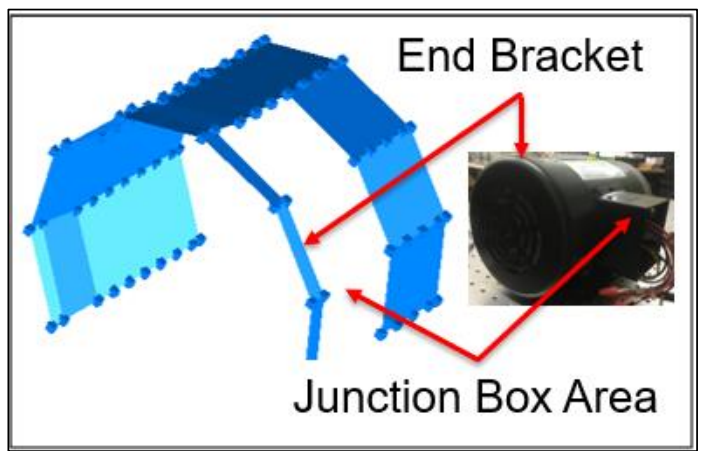

Figure 5. Rough motor geometry used in EMA and OMA.

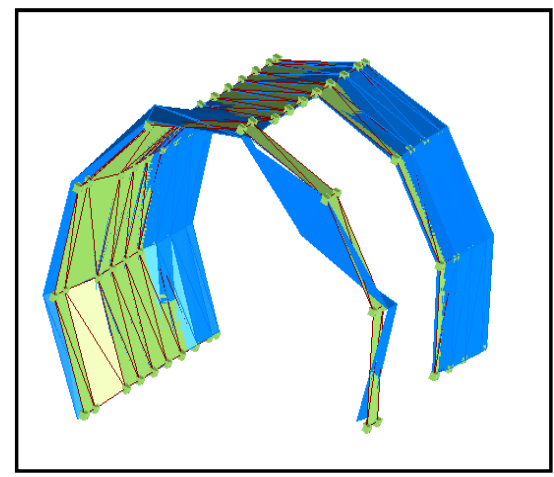

(a)

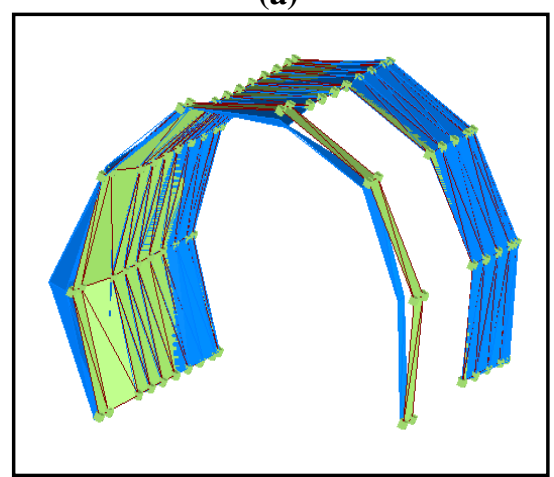

(c)

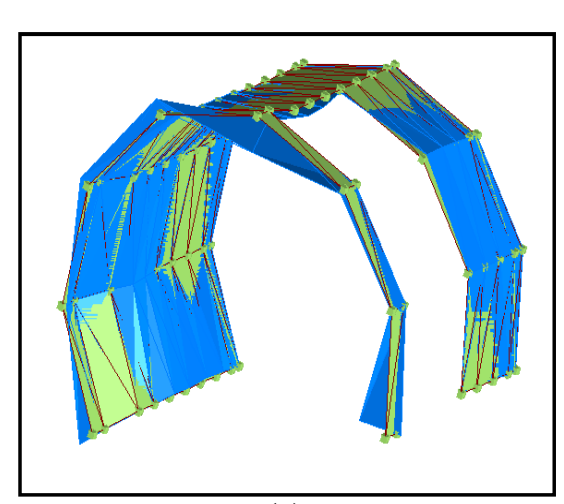

(e)

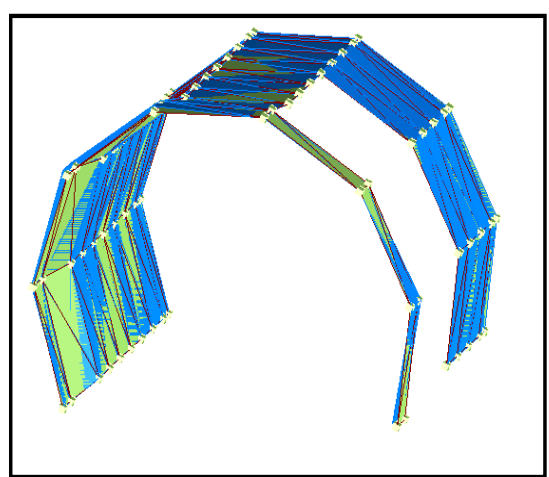

(b)

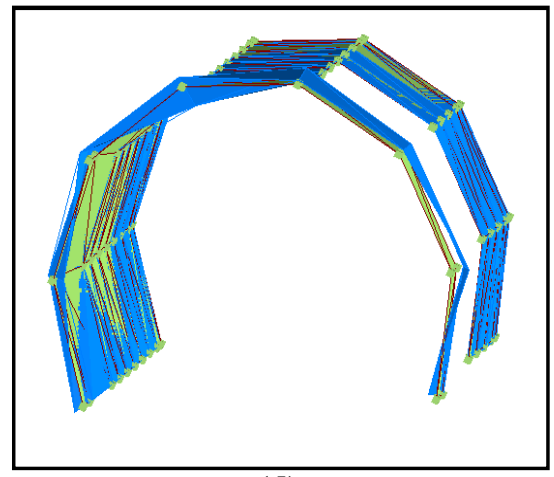

(d)

Figure 6. Operating deflection shape at (a) $424 \mathrm{~Hz}$, (b) $1164 \mathrm{~Hz}$, (c) $1439 \mathrm{~Hz}$, (d) $1943 \mathrm{~Hz}$, and (e) $2787 \mathrm{~Hz}$. 
A driving point FRF on the face of the shaft side of the motor housing, as seen from Figure 7, was also calculated, revealing two prominent resonances at 1830 and $3300 \mathrm{~Hz}$. The intent of carrying out these structural measurements was to eventually correlate with measured acoustic data in the semi-anechoic chamber.

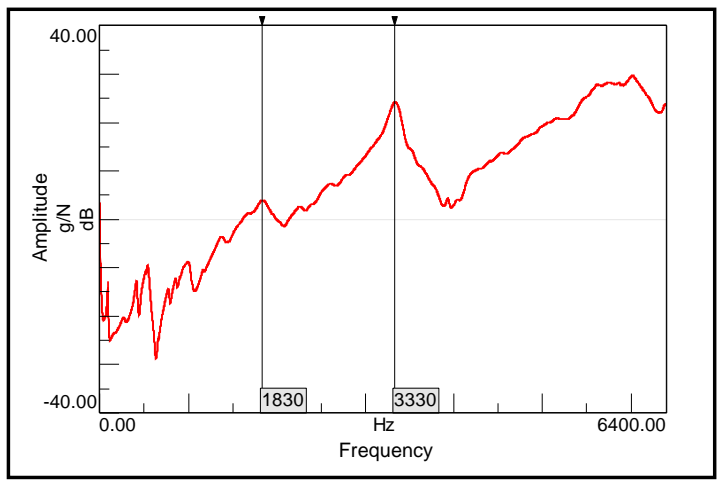

Figure 7. FRF from impact hammer test in the axial direction on the shaft side housing face.

\section{Acoustic Response and Correlation Study}

The auto-power spectrum calculated from the acoustic data captured by the shaft side microphone, as seen in Figure 8, revealed increased levels of sound pressure at 1824 and $3266 \mathrm{~Hz}$. These frequencies coincided with the resonance frequencies of the shaft-side face of the motor housing, as seen in Figure 9, which suggests that there could have been a breathing mode of the housing in the axial direction of the motor that was dominated by the shaft-side face. Furthermore, microphones in the other positions did not highlight these resonances, which promotes the idea of a contribution from an axially oriented flexural mode. It is clear that two structural resonances on the shaft side significantly contributed to the acoustic signature of the motor in that direction. It should be noted that the peaks highlighted in Figure 8 were independent of motor speed and thus indicative of structural modes that were excited regardless of the operating speed.

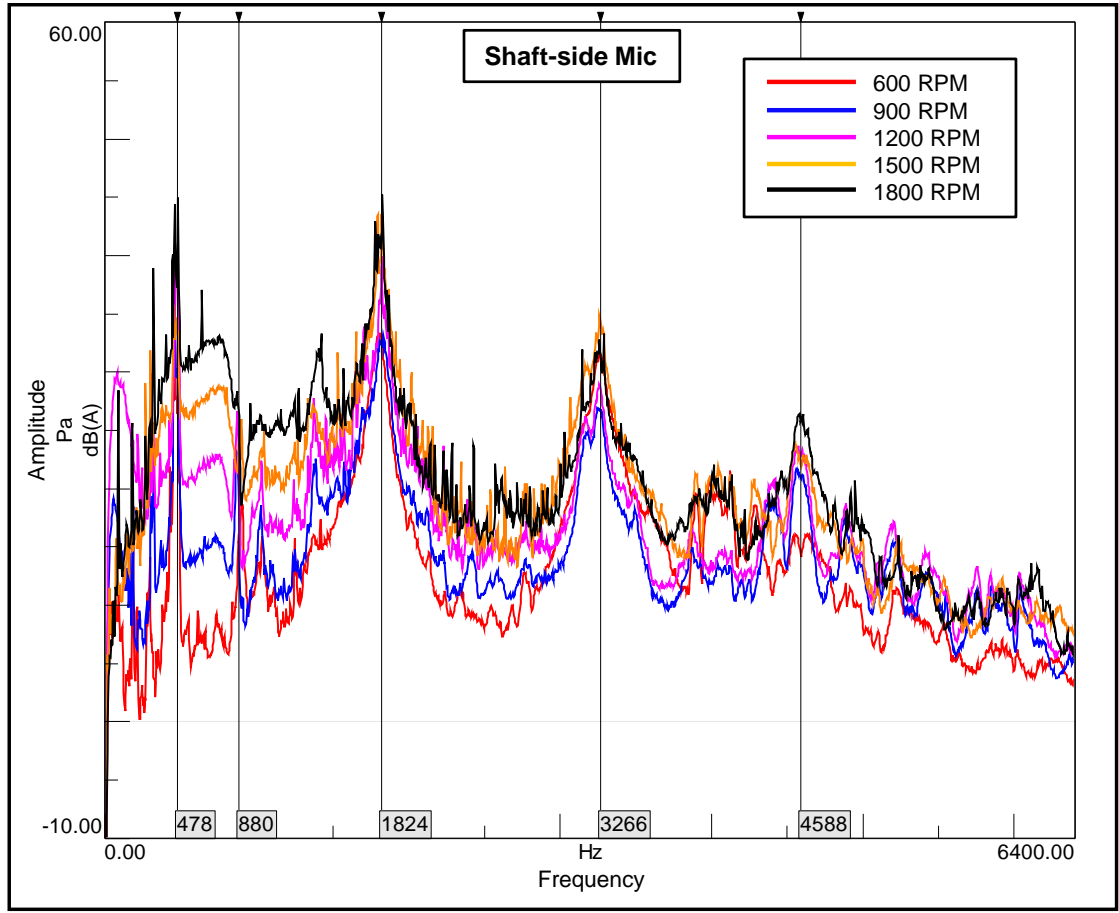

Figure 8. Acoustic auto-power spectrum from the shaft side microphone with RMS dB(A) values at synchronous speeds of 600, 900, 1200, 1500, and 1800 RPM. 


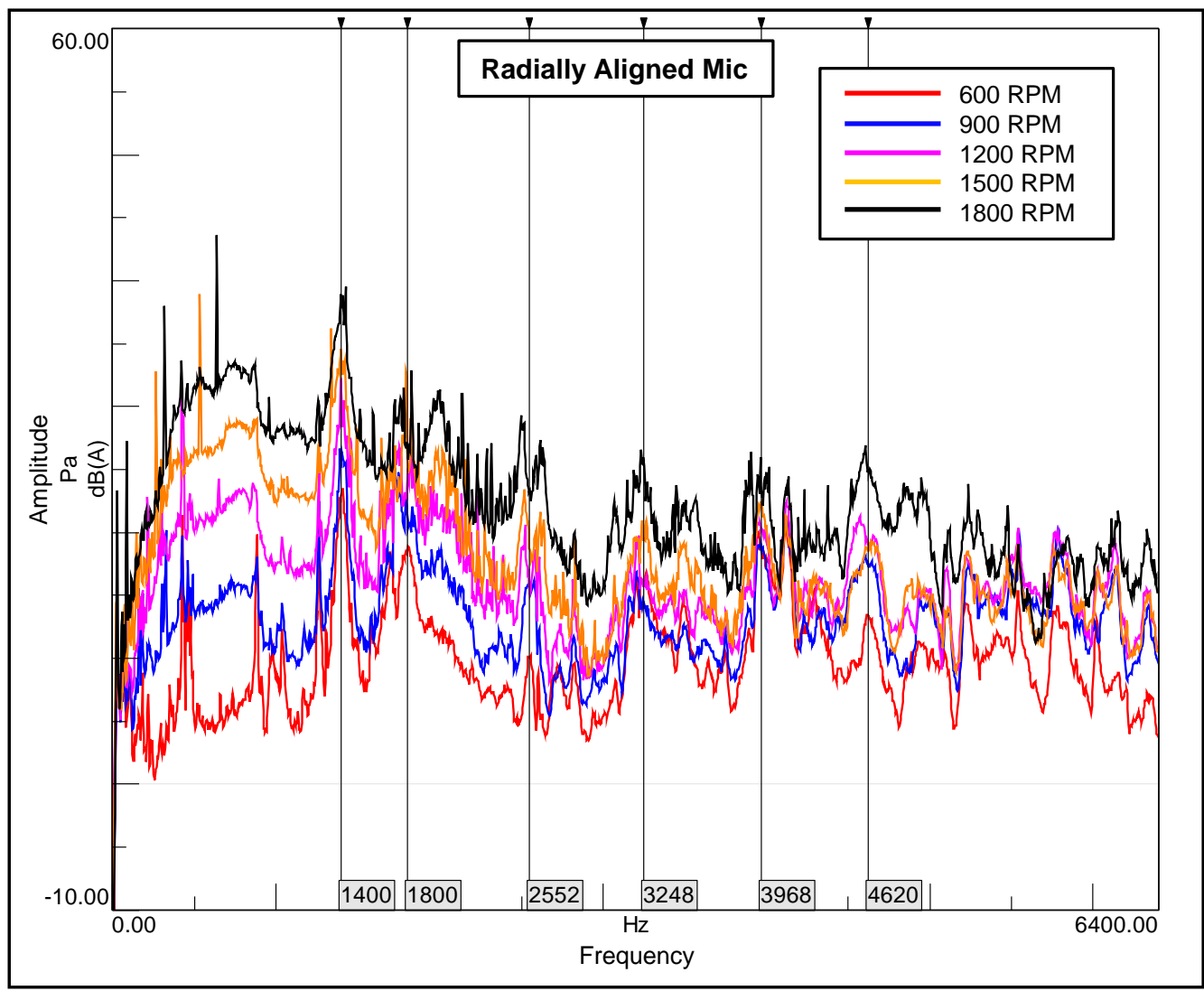

Figure 9. Acoustic auto-power spectrum from a microphone aligned in motor's radial direction with RMS dB(A) values at 600, 900, 1200, 1500, and 1800 rpm.

Comparing the auto-power spectrums calculated from the data captured at five discrete speeds by the radially aligned microphones (Figure 9), we found that a different set of resonance frequencies contributed to the acoustic signature of the sound traveling in the radial direction. Peaks at 1400, 1800, 2522, 3248, 3968, and $4620 \mathrm{~Hz}$ were some of the peak responses that particularly stood out. Three of these five frequencies can be correlated back to the operational modal analysis that was performed at 1800 RPM. The operational modal analysis especially highlights resonances at 1439 and $2644 \mathrm{~Hz}$. The resonance around $1400 \mathrm{~Hz}$ can be considered as a major contributor to the overall sound perceived. Zooming in to the spectrum below $1000 \mathrm{~Hz}$, as seen in Figure 10, revealed the fundamental fan blade passing frequencies (green circles) at the different speeds and their first harmonics (red circles). As shown in Figure 10, the fan blade passing frequencies had the highest amplitude levels for any given speed.

The auto-power spectrum calculated from the fan-side of the motor, as seen in Figure 11, highlighted most peaks that were observed in the two other directions. A zoomed-in view of the spectrum (Figure 12) shows fan blade passing frequencies marked by green and red circles and an apparent resonance close to $470 \mathrm{~Hz}$. This resonance at around $470 \mathrm{~Hz}$ can also be seen in the cross-power and summed frequency response function plots from the structural analysis. 


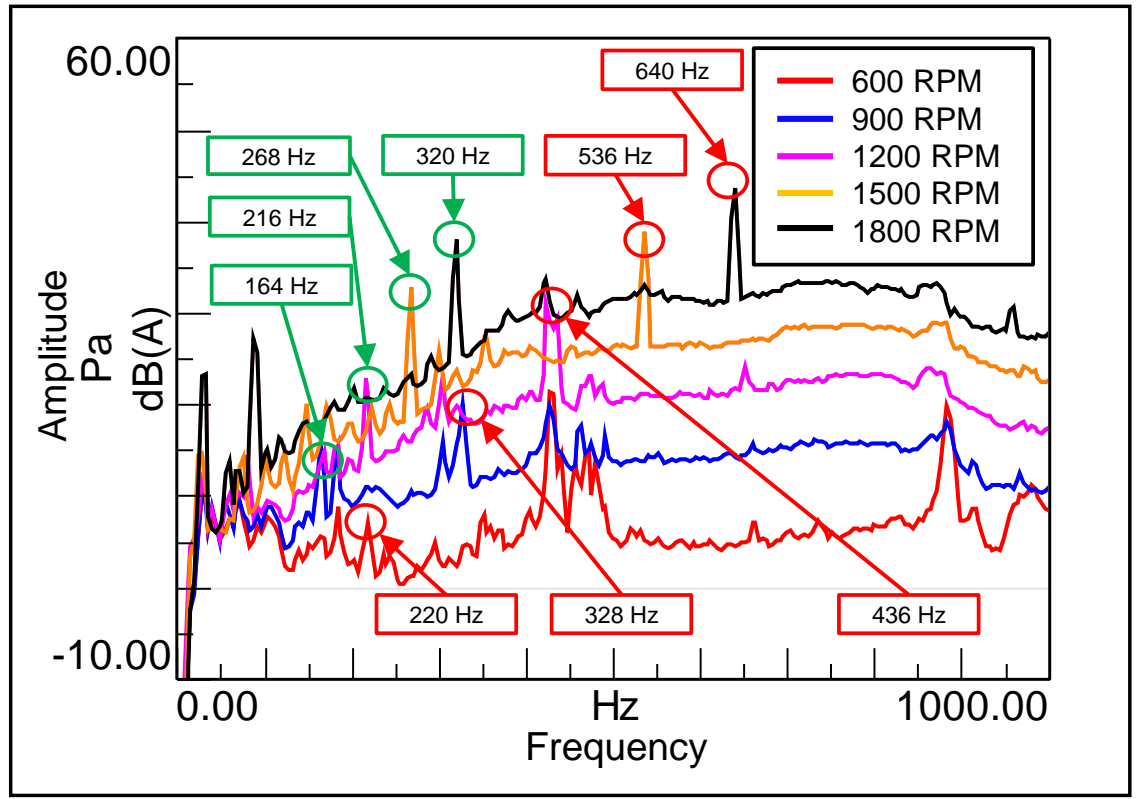

Figure 10. Zoomed-in acoustic auto-power spectrum from microphone aligned in motor's radial direction.

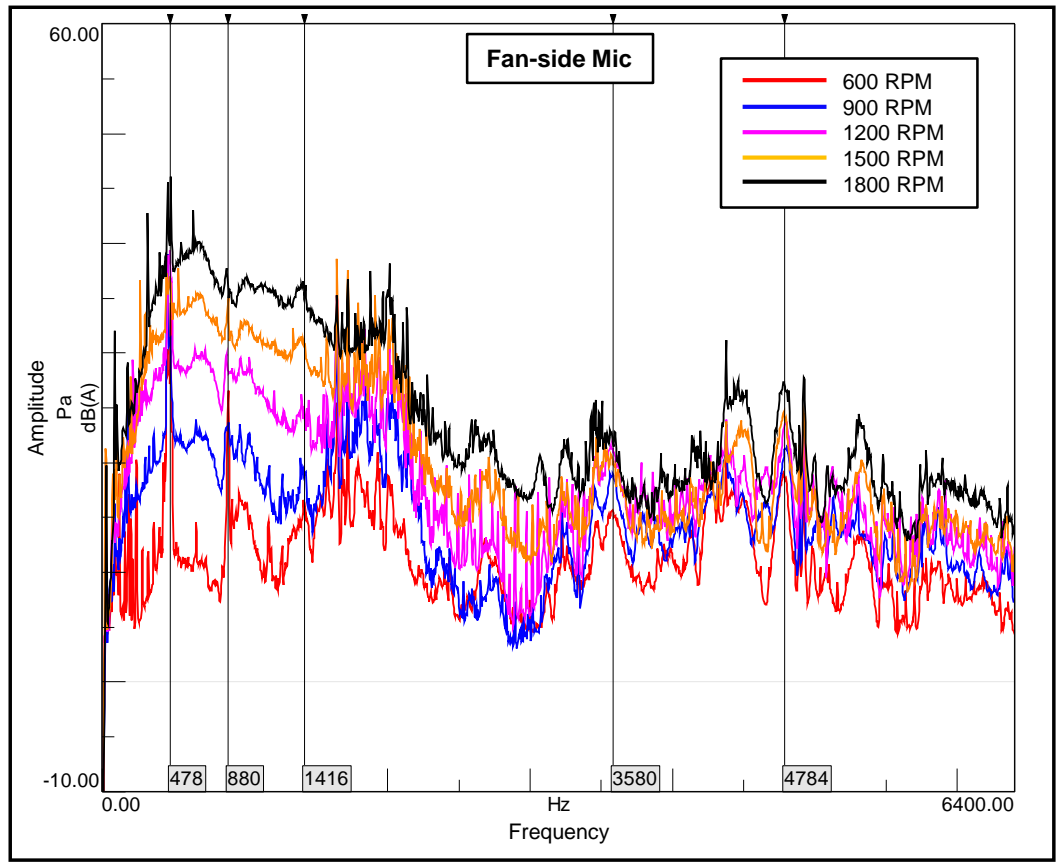

Figure 11. Acoustic auto-power spectrum from fan side microphone with RMS dB(A) values at 600, 900, 1200, 1500, and 1800 RPM.

\subsection{Sound Source Localization Using Overall SPL from Positional Microphone Data}

The overall sound pressure level from the three microphones, as seen from the schematic in Figure 3, were calculated as a function of time. It can be seen from the data in Table 1, the SPL generally increased with an increase in RPM (SPL at 600 and 900 RPM on the shaft side, however, were found to be identical). The sound measured at the fan end and the shaft end of the motor was especially higher than the sound measured in the radial direction. Upon a closer comparison of the fan and shaft side SPL values, it is interesting to note that at low speeds of 600 and $900 \mathrm{rpm}$, the SPL at the shaft end was greater than if not equal to the SPL at the fan end. For speeds above 1200 RPM, the fan 
side of the motor seemed to be the major contributor to the overall SPL. The SPL on the fan side of the motor was 1 to $5 \mathrm{~dB}$ higher than what was measured in the radial direction for speeds above 1200 RPM. This difference in SPL levels at the fan end of the motor helps realize the effect that it had on the overall sound perceived.

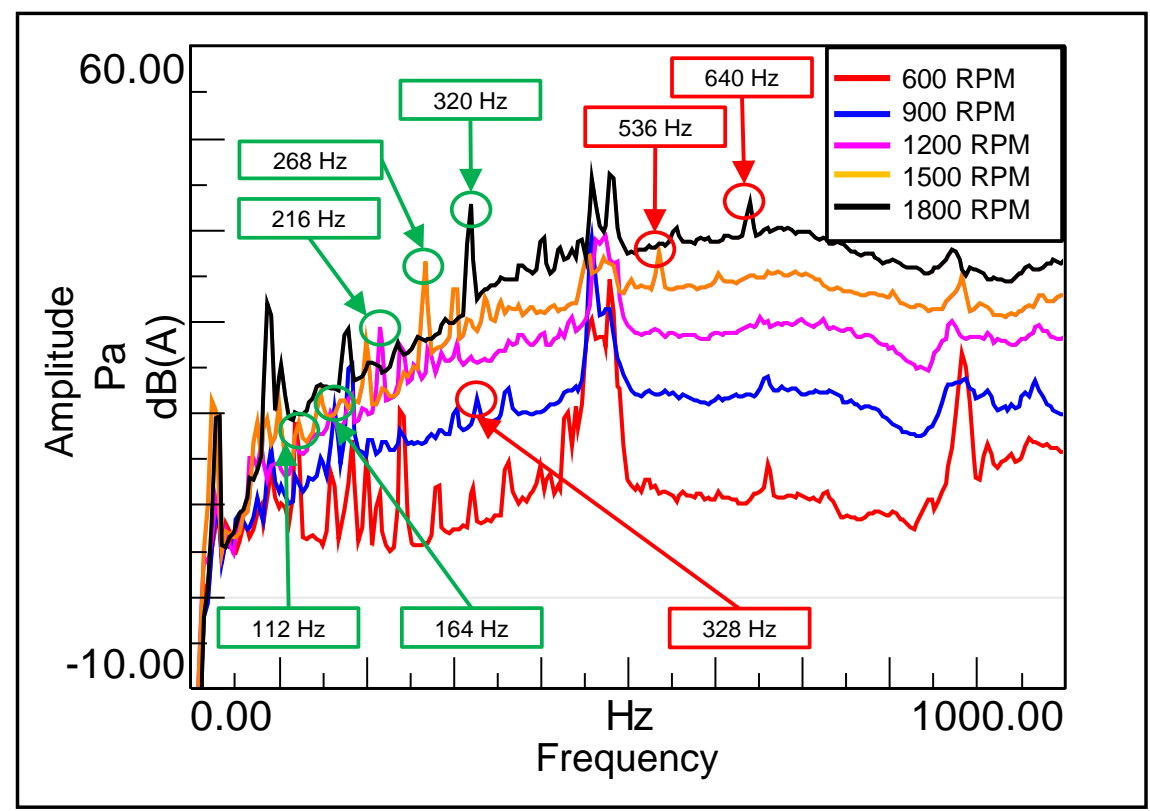

Figure 12. Zoomed-in acoustic auto-power spectrum from fan-side microphone.

Table 1. Overall sound pressure levels.

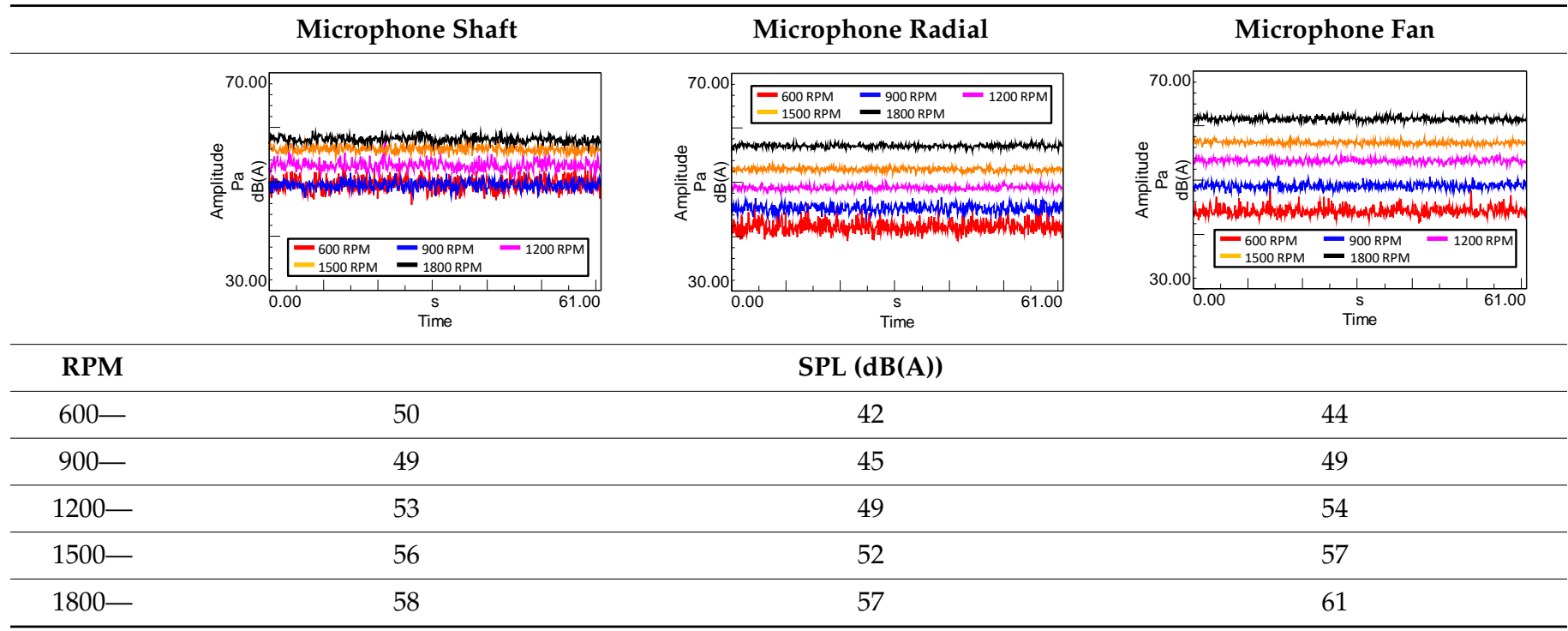

Table 1 helps narrow the focus down on the fan end of the motor, which seemed to have the greatest impact on the overall sound. The order analysis of the signal in the next section helps to break down some other contributors to the sound.

\subsection{Order Analysis of Acoustic and Vibration Data}

Order analysis was carried out by concatenating the individual measurement runs at synchronous speeds of 600, 900, 1200, 1500, and 1800 RPM. A handheld laser tachometer was used to measure RPM. The average order spectrum was calculated for the acoustic signals and the vibration signal on the motor housing. As shown in Figure 13, the averaged 
order spectra of SPLs measured using the three microphones clearly highlighted the fan blade passing 11th order (11 fan blades) and its first harmonic at $22(2 \times 11)$. The high amplitudes for low-frequency vibrations are less likely to be heard, owing to the hearing range of humans. An A-weighted filter on the spectra would attenuate the lower frequencies that are dominant in the spectra below but are not a true representation of human hearing. The fact that the fan blade passing orders were highlighted in all three microphones suggests that isolating fan noise could make a significant impact on the perceived sound.

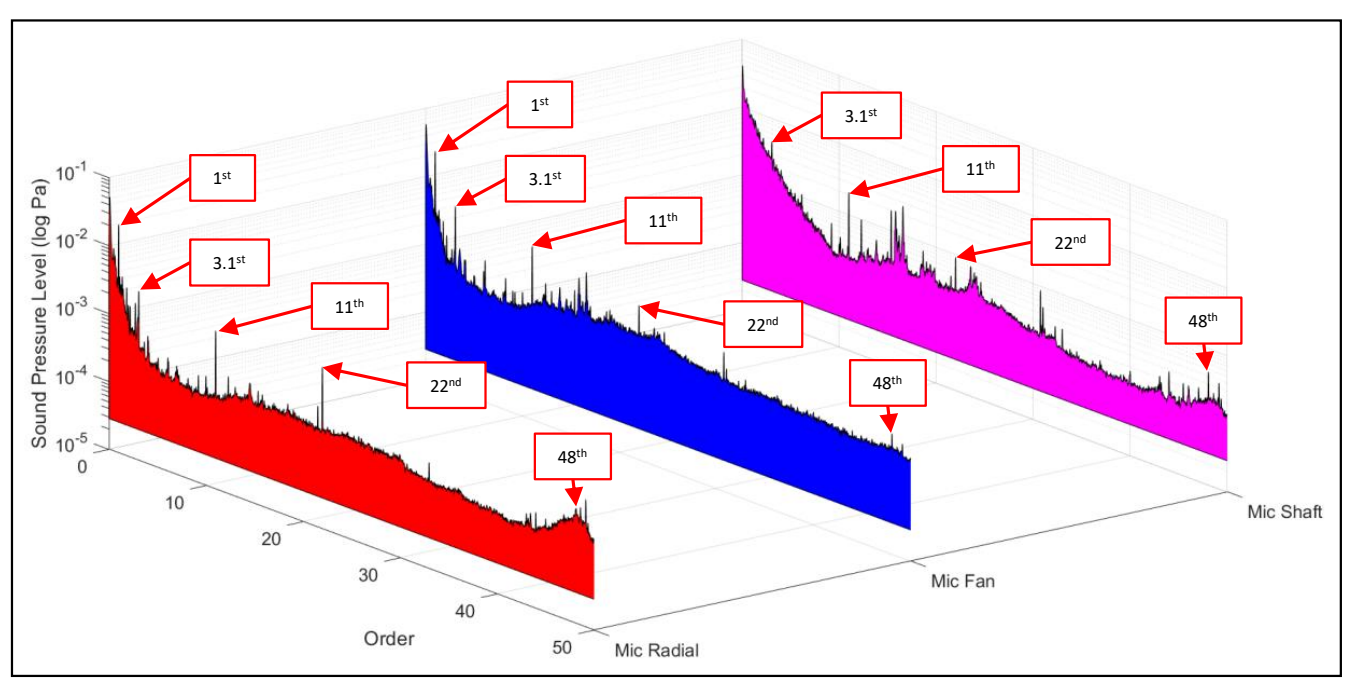

Figure 13. Average order spectra of sound pressure levels measured using radially aligned, fan-facing, and shaft-facing microphones.

The average order spectrum of the vibration signal measured on the motor housing exhibited other dominant orders that were not visible from the acoustic spectra. As shown in Figure 14, the first-order vibration was most dominant. Of the multiple phenomena that can cause first-order vibration to occur, two were plausible in this case. The first phenomenon could be dynamic eccentricity that causes air gap variations, especially in the case of induction motors, due to a very narrow air gap length design, which makes them very sensitive to slight defects. The second could be due to a mechanical imbalance in the rotor [35].

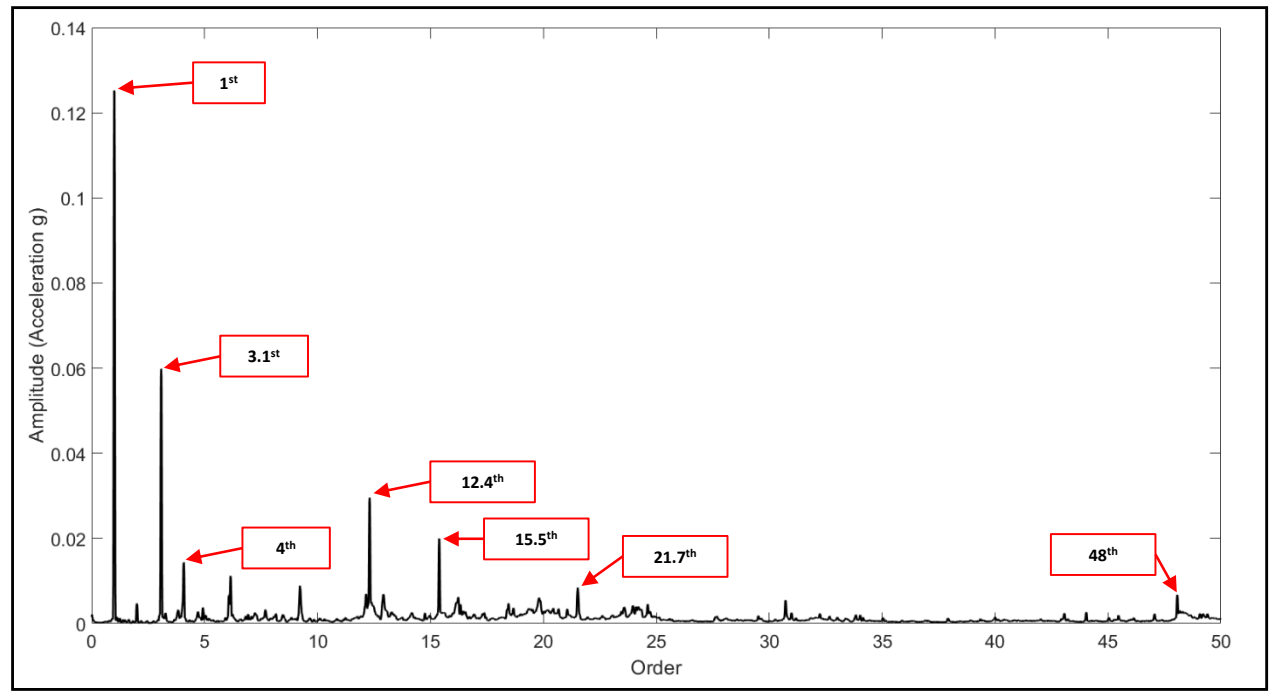

Figure 14. Average order spectrum of acceleration measured on the motor housing using a singleaxis accelerometer. 
The fourth-order vibration seen from the spectrum could be associated with the number of poles of the motor, four in this case, and is most likely linked to the electromagnetic interaction between the stator and rotor. The frequency corresponding to this fourth order was twice the electrical line frequency ( $2 X$ line frequency). The 3.1st order and its harmonics (12.3rd, 15.4th, and 21.5th orders) could be the result of a fault in the bearing outer race. SKF listed some bearing fault frequencies at $1500 \mathrm{RPM}(25 \mathrm{~Hz})$ [36] and showed that a 3.1st order can be the result of a fault in the outer race of the bearing $(76.3 \mathrm{~Hz} / 25 \mathrm{~Hz}=3.1)$.

The effect of high-frequency radial force slot harmonics due to interactions between rotor and stator harmonics can also be seen from the order analysis in Figures 13 and 14. The slots carrying the conductors in an induction motor generate a vibration force as they create unbalanced magnetic forces of attraction, resulting from an effective variation of reluctance in the magnetic circuit as a function of the rate of stator and rotor slot passing [18]. The frequency of radial forces for the four-pole induction motor used in this study, having 44 rotor bars and 36 stator teeth, is given by the following equation [37]:

$$
f_{r}=f_{l} k z_{r t}\left[\frac{1-s}{p} \pm 2\right]=f_{m}\left(k z_{r t} \pm 2 p\right) \pm 2 f_{s}
$$

where $f_{r}$ is the radial force-frequency; $f_{l}$ is the line frequency; $p$ is the number of pole pairs; $s$ represents slip; $z_{r t}$ is the number of rotor bars; $f_{m}$ is the rotational frequency; $f_{s}$ is the slip frequency; and $\mathrm{k}$ can assume positive integer values of $1,2,3$, etc.

The term $\left(k z_{r t} \pm 2 p\right)$ in this scenario can be 40 or 48 at $k=1$, which corresponds to the 40th or 48th order. These slot harmonic effects will be present in a healthy motor, owing to the presence of slots in the design, and changing the load on the motor should change the amplitude of the order associated with this effect.

\section{Conclusions}

Electric motors pose a different set of NVH challenges in comparison to the internal combustion engine, and the procedure to identify noise sources described in this paper can help better understand some of the contributors to the overall sound. Through structural analyses (i.e., modal analyses) and acoustic data processing (i.e., sound pressure autopower spectra), this paper aimed to make a correlation between the vibration of the motor housing and the sound captured by localized microphones. The correlation highlights certain resonances during normal operation of the motor under no-load that can be said to be significant contributors to the overall sound perceived. The resonances excited could very well be an effect of dynamic electromagnetic forces in the air gap between the stator and rotor. Some resonance frequencies, such as the shaft-side face resonances around 1800 and $3300 \mathrm{~Hz}$, helped to identify possible breathing mode shapes that are only captured by the microphone facing the shaft-side of the motor.

The comparison of overall sound pressure levels between the three different microphones led us to believe that the fan side of the motor was the loudest. The acoustic average order spectra were also consistent with what was found from the SPL comparison in that the fan blade passing fundamental frequencies, and their first harmonics were seen in all three directions analyzed. The 11th and 22nd order peak values also increased with an increase in motor RPM. This strongly suggests that tackling fan noise could help reduce the overall perceived sound. Bearing faults could also lead to increased levels of motor noise and usually contain harmonic content that can also interfere with structural resonances and accelerate wear. The fan-blade passing frequency and a possible fault in the outer race of the bearing were clearly the most prominent phenomena that the acoustic spectra underlined. Tonal frequencies such as the fan blade passing frequency could also be heard when the overall background noise was $10 \mathrm{~dB}$ higher, and efforts should hence be made to attenuate them. The 48 th order electromagnetic component generated due to high-frequency radial-force slot harmonics that were a product of the interactions between rotor and stator harmonics was observed in both the vibration and acoustic spectra. The amplitude of this component did not suggest an underlying issue, but changes in load, 
manufacturing defects, and poor motor designs could increase its influence on the overall perceived sound. This work was performed on a no-load motor. Under load, we can expect to see a similar envelope of the spectrum with amplified magnitudes and some critical frequencies shifting depending on the interaction with the loaded machine. It should be noted that the natural frequencies of the structure did not change due to load; however, the excitation frequency of the magnetic force can change by the applied load. The fan noise can be limited using encapsulation, active noise canceling, and sound-absorbing materials, or modifying the geometry. Furthermore, the geometry of the stator and rotor can be modified to ensure the natural frequencies of the motor were not close to the excitation frequencies.

While the proposed methodology did not directly tackle vibro-acoustics due to electromagnetic forces in the air gap, it provides an insight into a unique workflow to identify noise sources that constitute a major proportion of the acoustic signature of the motor. The technique described in this paper can surely be extended to fan-cooled motors that are used in vehicles such as golf carts or as auxiliary motors in EV/hybrid vehicles, as well as across a wide range of industrial applications.

Author Contributions: Conceptualization, J.B., D.L. and A.T.; methodology, J.B., D.L. and A.T.; software, A.K. and J.B.; validation, A.K., J.B., D.L., S.J.M.Y. and A.T.; formal analysis, A.K. and J.B.; investigation, A.K.; resources, J.B., D.L. and A.T.; data curation, A.K. and J.B.; writing-original draft preparation, A.K., J.B. and S.J.M.Y.; writing-review and editing, J.B., S.J.M.Y., D.L. and A.T.; visualization, A.K., S.J.M.Y.; supervision, J.B., D.L. and A.T.; project administration, J.B.; funding acquisition, J.B., D.L. and A.T. All authors have read and agreed to the published version of the manuscript.

Funding: This research presented in this paper is partly supported by a Kettering University Faculty Research Fellowship. Any opinions, findings, and conclusions, or recommendations expressed in this material are those of the author(s) and do not necessarily reflect the views of the sponsoring organizations.

Data Availability Statement: The data presented in this study are available upon request from the corresponding author.

Conflicts of Interest: The authors declare no conflict of interest.

\section{References}

1. Qin, Y.; Tang, X.; Jia, T.; Duan, Z.; Zhang, J.; Li, Y.; Zheng, L. Noise and vibration suppression in hybrid electric vehicles: State of the art and challenges. Renew. Sustain. Energy Rev. 2020, 124, 109782. [CrossRef]

2. Wellmann, T.; Tousignant, T.; Govindswamy, K.; Tomazic, D.; Steffens, C.; Janssen, P. NVH Aspects of Electric Drive Unit Development and Vehicle Integration; 0148-7191; SAE Technical Paper; SAE International: Warrendale, PA, USA, 2019.

3. Fang, Y.; Zhang, T. Sound quality of the acoustic noise radiated by PWM-fed electric powertrain. IEEE Trans. Ind. Electron. 2017, 65, 4534-4541. [CrossRef]

4. Poveda-Martínez, P.; Ramis-Soriano, J. Sound quality of small dc motors. Appl. Acoust. 2021, 176, 107898. [CrossRef]

5. Dos Santos, F.L.; Anthonis, J.; Naclerio, F.; Gyselinck, J.J.; Van der Auweraer, H.; Góes, L.C. Multiphysics NVH modeling: Simulation of a switched reluctance motor for an electric vehicle. IEEE Trans. Ind. Electron. 2013, 61, 469-476. [CrossRef]

6. He, S. NVH Design, Analysis and Optimization of Chevrolet Bolt Battery Electric Vehicle; 0148-7191; SAE Technical Paper; SAE International: Warrendale, PA, USA, 2018.

7. Wang, Y.; Gao, H.; Wang, H.; Ma, W. NVH Optimization Analysis of Permanent Magnet Synchronous Motor by Rotor Slotting. Vehicles 2020, 2, 16. [CrossRef]

8. Kotter, P.; Bischof, W.; Kennel, R.; Zirn, O.; Wegener, K. Noise-vibration-harshness-modeling and analysis of induction drives in E-mobility applications. In Proceedings of the 2017 IEEE International Electric Machines and Drives Conference (IEMDC), Miami, FL, USA, 21-24 May 2017; pp. 1-8.

9. Arabi, S.; Steyer, G.; Sun, Z.; Nyquist, J. Vibro-Acoustic Response Analysis of Electric Motor; 0148-7191; SAE Technical Paper; SAE International: Warrendale, PA, USA, 2017.

10. Patil, K.; Baqersad, J.; Behroozi, M. Experimental Modal Analysis on a Tyre-Lessons Learned. Int. J. Veh. Noise Vib. 2017, 13, 200-215. [CrossRef]

11. Baqersad, J.; Poozesh, P.; Niezrecki, C.; Avitabile, P. Photogrammetry and optical methods in structural dynamics-A review. Mech Syst. Signal Process. 2018, 86, 17-34. [CrossRef]

12. Panchal, R.; Horton, L.; Poozesh, P.; Baqersad, J.; Nasiriavanaki, M. Vibration analysis of healthy skin: Toward a noninvasive skin diagnosis methodology. J. Biomed. Opt. 2019, 24, 015001. [CrossRef] [PubMed] 
13. Sarrazin, M.; Janssens, K.; Claes, W.; Van der Auweraer, H. Electro-vibro-acoustic analysis of electric powertrain systems. In Proceedings of Fisita World Automotive Congress F2014-NVH-082; FISITA: Maastricht, The Netherlands, 2018.

14. Kotter, P.; Morisco, D.; Boesing, M.; Zirn, O.; Wegener, K. Noise-vibration-harshness-modeling and analysis of a permanentmagnetic disc rotor axial-flux electric motor. IEEE Trans. Magn. 2017, 54, 1-4. [CrossRef]

15. Mehrgou, M.; Zieher, F.; Priestner, C. NVH and Acoustics Analysis Solutions for Electric Drives; 0148-7191; SAE Technical Paper; SAE International: Warrendale, PA, USA, 2016.

16. Ágoston, K. Fault detection of the electrical motors based on vibration analysis. Procedia Technol. 2015, 19, 547-553. [CrossRef]

17. Principi, E.; Rossetti, D.; Squartini, S.; Piazza, F. Unsupervised electric motor fault detection by using deep autoencoders. IEEE/CAA J. Autom. Sin. 2019, 6, 441-451. [CrossRef]

18. Delgado-Arredondo, P.A.; Garcia-Perez, A.; Morinigo-Sotelo, D.; Osornio-Rios, R.A.; Avina-Cervantes, J.G.; Rostro-Gonzalez, H.; Romero-Troncoso, R.d.J. Comparative study of time-frequency decomposition techniques for fault detection in induction motors using vibration analysis during startup transient. Shock Vib. 2015, 2015, 708034. [CrossRef]

19. Chang, H.-C.; Jheng, Y.-M.; Kuo, C.-C.; Hsueh, Y.-M. Induction motors condition monitoring system with fault diagnosis using a hybrid approach. Energies 2019, 12, 1471. [CrossRef]

20. Ciaburro, G.; Iannace, G. Machine Learning-Based Algorithms to Knowledge Extraction from Time Series Data: A Review. Data 2021, 6, 55. [CrossRef]

21. Iannace, G.; Ciaburro, G.; Trematerra, A. Fault diagnosis for UAV blades using artificial neural network. Robotics 2019, 8, 59. [CrossRef]

22. Iannace, G.; Ciaburro, G.; Trematerra, A. Modelling sound absorption properties of broom fibers using artificial neural networks. Appl. Acoust. 2020, 163, 107239. [CrossRef]

23. Ciaburro, G.; Iannace, G. Improving smart cities safety using sound events detection based on deep neural network algorithms. Informatics 2020, 7, 23.

24. Henderson, B.S.; Huff, D.L. Electric Motor Noise Status. In Proceedings of the NASA ATWG Meeting, NASA Hampton, VA, USA, 11-12 April 2017; pp. 11-12.

25. Poozesh, P.; Aizawa, K.; Niezrecki, C.; Baqersad, J.; Inalpolat, M.; Heilmann, G. Structural health monitoring of wind turbine blades using acoustic microphone array. Struct. Health Monit. 2017, 16, 471-485. [CrossRef]

26. Di Marco, F.; D'Amico, R.; Ronzio, F. Electric motor encapsulation design for improved NVH: A CAE-based approach. In Proceedings of the INTER-NOISE and NOISE-CON Congress and Conference Proceedings, Madrid, Spain, 16-19 June 2019; pp. 2464-2474.

27. Gurav, R.; Udawant, K.D.; Rajamanickam, R.; Karanth, N.; Marathe, S. Mechanical and Aerodynamic Noise Prediction for Electric Vehicle Traction Motor and Its Validation; 0148-7191; SAE Technical Paper; SAE International: Warrendale, PA, USA, 2017.

28. Dupont, J.-B.; Aydoun, R.; Bouvet, P. Simulation of the noise radiated by an automotive electric motor: Influence of the motor defects. SAE Int. J. Altern. Powertrains 2014, 3, 310-320. [CrossRef]

29. Sathyan, S.; Aydin, U.; Belahcen, A. Acoustic noise computation of electrical motors using the boundary element method. Energies 2020, 13, 245. [CrossRef]

30. Saucy, H.; Dupont, J.-B.; Bouvet, P. Noise radiated by electric motors: Simulation process and overview of the optimization approaches. In Proceedings of the 32nd Electric Vehicle Symposium (EVS32), Lyon, France, 19-22 May 2019.

31. Gieras, J.F.; Wang, C.; Lai, J.C. Noise of Polyphase Electric Motors; CRC Press: Boca Raton, FL, USA, 2018.

32. Poozesh, P.; Sabino, D.D.; Baqersad, J.; Avitabile, P.; Niezrecki, C. Practical Techniques for Scaling of Optically Measured Operating Deflection Shapes. In Rotating Machinery, Hybrid Test Methods, Vibro-Acoustics \& Laser Vibrometry, Volume 8; Springer: Berlin/Heidelberg, Germany, 2016; pp. 1-17.

33. Baqersad, J.; Poozesh, P.; Niezrecki, C.; Avitabile, P. Comparison of modal parameters extracted using MIMO, SIMO, and impact hammer tests on a three-bladed wind Turbine. In Topics in Modal Analysis II, Volume 8; Springer: Berlin/Heidelberg, Germany, 2014; pp. 185-197.

34. Krishnasarma, A.; Taylor, A.; Baqersad, J.; Poozesh, P. Structural Vibration and Acoustic Analysis of a 3-Phase AC Induction Motor; 0148-7191; SAE Technical Paper; SAE International: Warrendale, PA, USA, 2019.

35. Bate, G.H. Vibration Diagnostics for Industrial Electric Motor Drives, Brüel and Kjaer Application Note (1990). Available online: https:/ / www.bksv.com/media/doc/BO0269.pdf (accessed on 2 August 2021).

36. SKF. SKF Bearing Select, Version: 1.2.55. Available online: https:/ / skfbearingselect.com/\#/ one-or-two (accessed on 2 August 2021).

37. Tsypkin, M. The origin of the electromagnetic vibration of induction motors operating in modern industry: Practical experienceAnalysis and diagnostics. IEEE Trans. Ind. Appl. 2016, 53, 1669-1676. [CrossRef] 